\title{
Entrepreneurial career resilience and entrepreneurial career success: Does entrepreneurial career commitment matter?
}

\author{
Isyaku Salisu $^{a^{*}}$, Norashida Hashim ${ }^{\mathrm{b}}$ and Aliyu Hamza Galadanchic
}

${ }^{a}$ Department of Business Administration,Umaru Musa Yar'adua University, Katsina, Katsina State, Nigeria

${ }^{b}$ School of Business Management, College of Business, Universiti Utara Malaysia (UUM) 06010 Sintok, Kedah Darul Aman Malaysia, Malaysia

${ }^{c}$ Bursary Department, Ulul-Albab Science Secondary School, Katsina, Katsina State, Nigeria

C H R O N I C L E

Article history:

Received: September 20, 2018

Received in revised format: Sep-

tember 30, 2018

Accepted: October 20, 2018

Available online:

October 20, 2018

Keywords:

Entrepreneurial

Career

Success

Commitment

Resilience

Nigeria

\section{Introduction}

Previous studies in the management discus have long documented that outcomes of entrepreneurial activities affect the global economy and hence many of these works have put more weight on the outcomes of these entrepreneurial activities. But, despite many studies on the characteristics of entrepreneurial organizations and individuals, and their consistent correlations with diverse entrepreneurial outcomes, Ramana et al. (2008) argued that success of an entrepreneur is one of the topics that received less attention. Additionally, works on success emphasizes more on the success of the organization (Brush et al., 2008) such as industry, market leadership or business growth, company volume such as sales, employment, revenue, assets and/or market share rather than the individual owners of these organizations

* Corresponding author.

E-mail address: abdaratsauri@gmail.com (I. Salisu)

(C) 2019 by the authors; licensee Growing Science, Canada doi: $10.5267 /$ j.msl.2018.10.014 
(Walker \& Brown 2004; Shane et al., 2003). Further, majority of the literature on success of an entrepreneur emphasize on its objective and financial aspect (König et al., 2012) hence, overlooking the entrepreneurs' idiosyncratic evaluation of their success (Dej et al., 2013) such as their intrinsic satisfaction or achievement. Paige and Littrell (2002) buttress that, traditional financial indicators such as income and profits earned by entrepreneurs do not account much more than their self-actualization. More importantly, Goal Content Theory (Deci \& Ryan, 1985) conceived that attaining intrinsic goals are more imperative to an individual as they increase positive outcomes then the extrinsic which are adversely related to individual's positive outcomes. Therefore, the focus of this paper is on the individual level career success which refers to the appraisal of their career experience (Judge et al., 1999). Specifically, subjective aspect which represents "less tangible, personal judgments of one's career based on criteria deemed important to the individual” (McDonald, \& Hite, 2008, p. 89)

However, earlier researchers have been intensely concerned about exploring the determinants of career success both at the level of individual, group and organization (Payne et al., 2011). In this regard, some of the elements that acknowledged serious attention are resilience (Bhamra, 2015) and commitment (Chiang et al., 2014). For resilience on one hand, it has been argued that entrepreneur who displays great level of risk tolerance for threat, uncertainty and quick adaptation to change, may be prepared to achieve superb result (Ayala \& Manzano, 2014). Entrepreneurs who exhibit resilience traits are keen and ever ready to work determinedly to achieve their objectives. They swiftly respond to environmental fluctuations to discover novel opportunities and are ready to learn and mend from their earlier mistakes (Cooper et al., 2004). Therefore, many scholars hypothesized that prosperous entrepreneurs are artefact of resilience (Hayward et al., 2010). Although it is crucial for entrepreneurial success, this construct has received scant attention in the entrepreneurial literature (Bullough \& Renko, 2013; Hussels et al., 2013) most especially in developing economies (Abiola \& Udofia, 2011). In addition, it basically remains vague, what entrepreneurial resilience essentially refers to and which possible factors (e.g. specific factors) aid to develop and improve this individual capacity (Duchek, 2018). In this paper, we aimed at responding to this research gap by constructing a thoughtful understanding of the complex nature of this construct and important influencing element (commitment) and outcome (career success).

On the other hand, commitment is a valuable measure of success, which has drawn the attention of both academic researchers and practitioners for decades, with so many literatures and inferences on its impact and values. It is regarded as a vital aspect in the entrepreneurial process that is capable of routing small and medium enterprises (SMEs) to success (Chiang et al., 2014). But, in spite of the eminent role it plays, its applicability and its theories in the entrepreneurial discus has been understudied, (Fayolle \& Liñán 2014). Moreover, most of the studies that integrate commitment into entrepreneurial process have related it to intention of the entrepreneurs not their action (De Clercq et al., 2009).

Therefore, the current study adds to the existing body of knowledge by exploring the interplay of entrepreneurial career commitment (ECC) and entrepreneurial career resilience (ECR) in predicting entrepreneurial career success (ECS) in the context of Africa, specifically, Nigeria. We argued that, although, entrepreneurs have what it takes to succeed in terms of personal resources (resilience), they also need to be committed. It is because they are resilient, that is why they are more committed and consequently achieve success in their career. Additionally, most of studies and theories on the effect of personal capital variables have directly linked them to their outcomes. We therefore argued in this paper that these variables must not necessarily be linked directly as they could be indirectly linked. So in addition to the examination of the direct relationships among the mentioned variables, this paper adds to knowledge on career success by examining the indirect effect of ECC.

\section{Literature Review}

\subsection{Entrepreneurial Career Success}

Career success has been one of the fundamental constructs in the career literature, that has been suggested as critically inducing the way and manner an individual perceive and react to their career development, 
(Pan \& Zhou, 2015). Consequently, it has attracted serious attention from researchers, practitioners and policy makers both at individuals as well as organizational level. Several scholars attempted to define the career success, but, from the various definitions consulted, it was understood that they shared the same view as to what career success entails. Thus, it is the total positive and desirable outcome individuals achieved through their career experience (Arthur et al., 2005; Judge et al., 1999).

Career success is not only about organizations and employees, but also the owners of the organization (entrepreneurs) because their success can ultimately hint to the success of their organizations. However, from occupational perspective, career success of the entrepreneur differs from that of employees of an organization. For instance, level in the organizational hierarchy, salary and promotion have been used for long to explain the career success of employees, but these are inadequate for assessing entrepreneurs who are the owner/managers of their organizations (Lau et al., 2007). As such, different scholars delve in search of what makes career success of an entrepreneur (e.g. Liu et al., 2015). One prominent work that clearly delineates this is Lau et al., (2007) who explicitly categorized career success of an entrepreneur from the view point of objective and subjective aspect. The former being the extrinsic achievement such as income, reputation and recognition. The latter on the other hand is the intrinsic component consisting of elements such as career satisfaction (CS), perceived career achievement (PCA) and perceived financial attainment (PFA). Based on this, this study intends to exploit some of the predictors of the subjective components of ECS. According to Lau et al. (2007, p. 129), PFA is the "positive outcomes at work based on personal appraisal in terms of financial attainment". PCA is an "indirect perception of their real achievement" (Bonesrønning, 2004, p.152) and CS refers to individual satisfaction with different aspects of career advancement and success (Parasuraman et al., 1996)

\subsection{Entrepreneurial Career Resilience}

Defined as "a unique ability to endure and recover fully from the extreme conditions, setbacks, trauma and other adversity." (Paul \& Garg, 2014, p. 72), resilience has received solemn consideration for over 50 decades, Abramson et al. (2014) and earlier researches in different fields of research have established that resilience is connected to various outcomes. The construct is related to subjective career success of entrepreneurs (Salisu et al., 2017; Robinson et al., 2016). For instance, Markman et al., (2005) supported that resilience plays a key role in influencing the success of entrepreneurs. This made Hayward et al. (2010) to argue that the more the resilience in the entrepreneurial environment, the more the entrepreneurial success and the less it is the opposite. Tait (2008) advocated that resilience is very prominent predictor of individuals' success and commitment. An individual who exhibits resilience is able to control his or her emotions and intermingle more effectively in social environments, and thereby achieve success. Also, Richtnér, and Löfsten, (2014) argued that success is a function of an individual's ability to bounce back after major setback. Likewise, in their framework for the study of resilience, Bonanno et al. (2015) buttress that resilience is a significant predictor of career success. Therefore, if it is assumed to be indispensable to any business venture, it is logical to say that without resilience attributes, entrepreneur in turbulent settings such as Nigeria will never operate successfully. To this, therefore, the current study hypothesised that:

$\mathrm{H}^{1}$ - There is a positive relationship between ECR and CS.

$\mathrm{H}^{2}-$ There is a positive relationship between ECR and PCA.

$\mathrm{H}^{3}-$ There is a positive relationship between ECR and PFA.

Resilience is also found to be related to commitment. Most of the previous studies documented positive link between this psychological construct and commitment and therefore they maintained that it is a striking predictor of commitment both at the level of organization and individual (e.g. Salisu et al., 2018). For instance, Hasan (2016) examined the direct and indirect relationship between the resilience and commitment. It was found to be significant directly and indirectly through culture. Lee and Cha (2015) investigated the social worker's resilience and its possible impact on their satisfaction and commitment. The study established the significant positive association among resilience, satisfaction and commitment. 
In the same vein, $\mathrm{Gu}$ (2014) investigated the role played by teacher's resilience in promoting commitment. The study found the resilience of teachers correlated with the teachers' commitment. Cho et al. (2014) studied the influence of resilience on commitment of dental hygienists in Korea. Consistently, the authors concluded that commitment of the dental hygienists increased when they were resilient. Another importance finding on the link between resilience and commitment was in the study of Shahbazfar and Zarei (2014). The authors used three Meyer and Allen's (1991) dimensions of commitment (normative, affective and continuance). From their analysis, all the three dimensions of commitment were influenced by resilience. Finally, a study by Seo et al. (2014) who investigated the nexus among resilience, satisfaction and commitment, discovered yet another significant positive relationship. We therefore hypothesized that:

$\mathrm{H}^{4}$ - There is a positive relationship between ECR and ECC.

\subsection{Entrepreneurial Career Commitment}

Career commitment denotes individuals' identification with and involvement in their occupation. Specifically, it refers to peoples' motivation to work in their preferred vocation (Hall, 1971). According to Klein et al. (2014, p.137,), it is "volitional psychological bond reflecting dedication to and responsibility for a particular target". It is argued, individuals who are committed to their careers should experience more career success than those who are less committed. Therefore, committed individuals are ever willing to make substantial investments in their careers by putting more energy and determination, acquiring novel skills and knowledge and subsequently experience innate career success (Poon, 2004).

Career commitment is among the profiles for successful individuals and unarguably, it has been shown to affect success in various ways. For instance, Karavardar, (2014) study the role of commitment on career success of employees in hazelnut processing industry, Giresun/turkey. The study shows that the two constructs are significantly correlated. Likewise, Srikanth \& Israel (2012) conducted an empirical study on the relationship between career commitment and career success through indirect effect of career satisfaction in manufacturing and information technology companies in India. Their regression analysis revealed that career commitment predicts career success as well as career satisfaction. More so, Ballout, (2009) and Poon, (2004) documented a significant positive relationship between commitment and the two facets of success - subjective (career satisfaction) and objective (Salary). More interestingly, the KUT scale, which was used in this study, was also found to positively predict satisfaction (Klein et al 2014). We therefore proposed that:

$\mathrm{H}^{5}$ - There is a positive relationship between ECC and CS.

$\mathrm{H}^{6}-$ There is a positive relationship between ECC and PCA.

$\mathrm{H}^{7}$ - There is a positive relationship between ECC and PFA

Additionally, evidences have demonstrated a strong link between resilience and commitment on one hand, and commitment and career success on the other hand. But, despite the consistent form of findings in which resilience and other related variables interrelated positively with career success, little is acknowledged about the mechanisms underlying these consistent interrelations. One possible intermediary of the links between the independents and dependent variables in this paper is ECC. Several studies have employed commitment as an intervening variable in various relationships (e.g. Sharma, \& Dhar, 2016; Farrell et al., 2015). Therefore, we stated that:

$\mathrm{H}^{8}$ - ECC mediates the positive relationship between ECR and CS.

$\mathrm{H}^{9}-\mathrm{ECC}$ mediates the positive relationship between ECR and PCA.

$\mathrm{H}^{10}-\mathrm{ECC}$ mediates the positive relationship between ECR and PFA. 


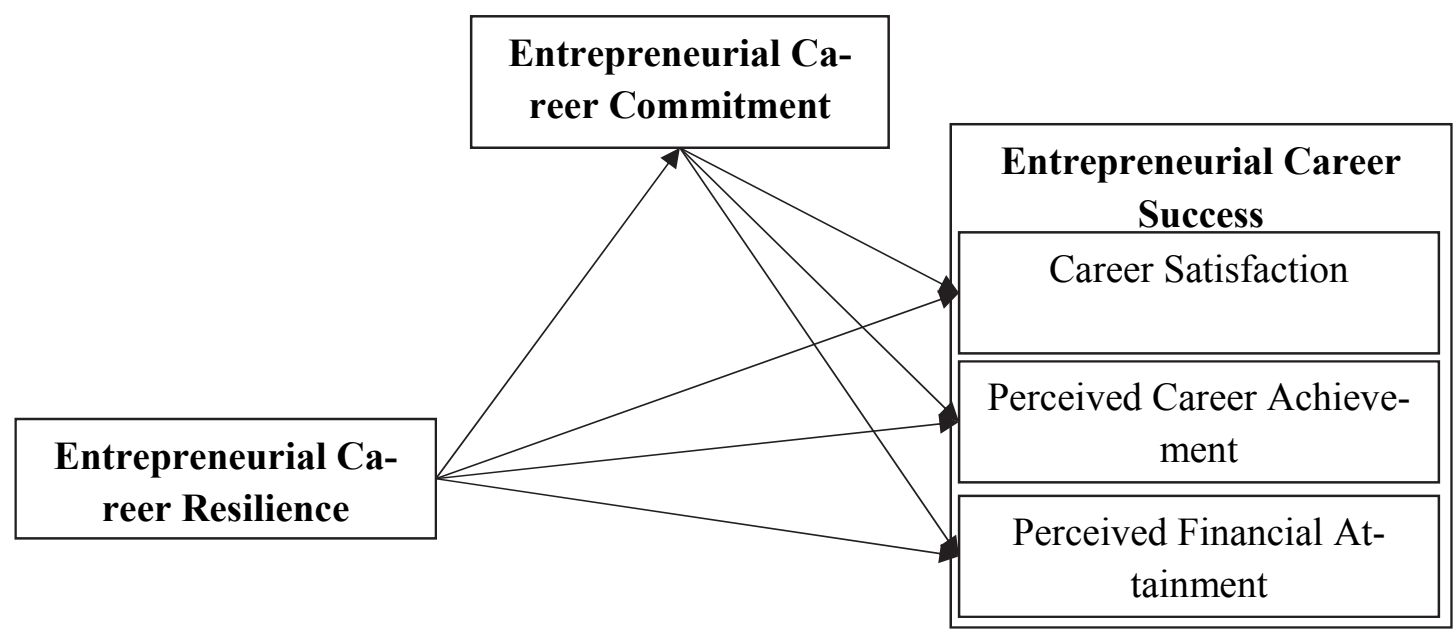

Fig. 1. Hypothesized Model

\section{Material and Methods}

Quantitative studies depend heavily on standardized scale to measure a given construct. Survey questionnaire is one of these standardized tools, which can be used to measure beliefs and attitudes across a range of topics and also to get fairly accurate information. In this paper, self-administered questionnaire is adopted. 576 respondents were selected using purposive sampling technique. The paper adopts crosssectional approach where the data was collected at once.

Out of 576 questionnaires distributed, $390(68 \%)$ were retrieved and therefore used for data analysis. Most of the respondents of this study were males consisting of 342 or $87.7 \%$ against females 48 or $12.3 \%$. This whopping percentage of male entrepreneurs has shown their dominant role in entrepreneurial arena and previous studies have shown that generally, women are far left behind in business creation activities (García \& Capitán, 2016). Also, married people are more in the sample than any other marital status category where 280 or $71.8 \%$ respondent were married, 107 or $27.4 \%$ were single, 2 or $0.5 \%$ were widowed and 1 or $0.3 \%$ divorcee. The respondents also vary in terms of their educational qualification but the majority of them were graduates with either B.Sc/HND (159 or 40.7\%), Master degree (76 or 19.5\%) and doctorate degree (14 or $3.6 \%$ ). In addition, 48 or $12.3 \%$ possess only secondary school certificate while 83 or $21.3 \%$ have ordinary national diploma or national certificate of education. But, there are other 10 or $2.6 \%$ of the respondents that possess educational qualifications other than the ones categorized. Overall, those with first degree participated most in this study.

The age of the respondent, years of experience in their current industries and years of experience in startups were continuous variables and therefore their mean and standard deviations were determined. From the table, the mean and standard deviation of age of the respondents were 36 and 10, respectively. While years of experience in their current industries and years of experience in start-ups have mean of 10 and standard deviation of 7 each.

\section{Measures}

Although there are various scales used to measure the constructs of this study in the previous researches, we selected the best based on their psychometric properties and their applicability and/or currency. However, to moderate the consequence of methods bias, these measurements were adapted/adopted from diverse sources, each of the variables is measured using established scale developed by different authors rather than adopting/adapting all the variable's measurement from a single author (Podsakoff et al., 2012). In addition, all items were rated in 5-point Likert scale. 
This paper measures four variables. First, ECS was measured using three subscales CS, five (5) items adapted from Greenhaus et al.(1990). The sample of the questions is "I am satisfied with the success I have achieved in my career", PCA, five (5) items. The sample of the questions is "I have a sense of achievement from my career" and PFA, four (4) items, sample of the questions is "I have earned more money than most of my friends" adopted from Lau et al., (2007). Second, ECR was measured by unidimensional 10 items Connor and Davidson's (2003) Resilience Scale (CD-RISC-10) by Campbell-Sills and Stein (2007). It is one of the best available measures of individual resilience (Salisu \& Hashim, 2017). Sample of the item include, "I tend to bounce back after illness or hardship". Third, ECC was measure by Klein et al. (2014), Unidimensional Target-free (KUT) developed by Klein et al. (2014) based on Klein et al., (2012) conceptualization. Example of the questions are "How committed are you to your career". The use of this scale was suggested by Klein et al. (2014) that future work on commitment should use the scale to evaluate different commitment outcomes in different context. (See appendix 1 for full scales)

\section{Data Analysis}

There are so many analytical/statistical tools of data analysis. However, considering the constructs and their measurements in this study, Partial least square structural equation modelling (PLS-SEM) using Smart-PLS 3 is adopted. This tool is increasingly being used to analyse data in various field of studies (Sarstedt et al., 2014; Hair et al., 2012). It is a variance based structural equation modelling method that can assess both inner and outer models (Henseler et al., 2009). It is the most widely used tools in social and behavioural science researches in examining quantitative data (Lee et al., 2011). It exhibits more statistical power than most of the statistical tools available. It has distinctive capability of analysing data that is not normal, and data from a small sample size. It also handles complicated frameworks such as assessment of hierarchical component model (Hair et al., 2014; Hair et al., 2013).

\section{Result}

\subsection{Descriptive statistics}

The latent variables' descriptive statistics in this study was computed using their mean and standard deviation. The results are shown in Table 1 and for easy and simple interpretation, the responses to the five-point Likert scale were categorized into three namely: mean of $\leq 2.4$ - low, mean of 2.5 to 3.4 moderate and mean of $\geq 3.5$ - high (Zhang, \& Wu, 2009). The overall mean value of all the variables under consideration ranged between 2.995 and 4.131. Specifically, the mean values of CSS and PCA were 3.626, 3.924, respectively. This indicates that respondents have high level of CSS and PCA. Mean values of PFA was 2.995 which showed the respondents' moderate level of PFA. Additionally, resilience and commitment have the mean of 3.939, 4.131, respectively, which signifies that the respondents have high level of resilience and commitment. Additionally, the standard deviation from all the construct have values ranging from 0.544 to 0.816 , being values for resilience and commitment, respectively. These values prove the existence of adequate variability in the data set.

\section{Table 1}

Descriptive Statistics for all Research Constructs of the Study

\begin{tabular}{llcccccc}
\hline Research Variables & Code & $\begin{array}{c}\text { No. of Respond- } \\
\text { ents }\end{array}$ & $\begin{array}{c}\text { No. of } \\
\text { Items }\end{array}$ & Min & Max & Mean & Std. Deviation \\
\hline CSS & CSS & 390 & 5 & 1 & 5 & 3.626 & 0.779 \\
\hline PCA & PCA & 390 & 4 & 1 & 5 & 3.924 & 0.616 \\
\hline PFA & PFA & 390 & 5 & 1 & 5 & 2.995 & 0.739 \\
Resilience & RES & 390 & 10 & 2 & 5 & 3.939 & 0.544 \\
Commitment & COM & 390 & 4 & 1 & 5 & 4.131 & 0.816 \\
\hline
\end{tabular}




\subsection{Common Method Variance (CMV)}

CMV is a serious methodological problem which affects the estimates of reliability and validity of a scale especially when the data were collected using self-administered questionnaire (Jakobsen, \& Jensen, 2015) or collected from a single source (Podsakoff et al., 2003). To mitigate the detrimental influence of CMV, this study used measures such as, procedural remedies (Podsakoff et al., 2012) such as notifying the respondents there is no right or wrong answer and their confidentiality is guaranteed. In addition, a Post-hoc test, specifically, Harman's One Factor Test (Podsakoff et al., 2013) was conducted, which produces eigenvalues that show no individual factor accounted for more than $50 \%$ of the variance and the first factor accounted for only $17.7 \%$ of the total variances (Podsakoff et al., 2012) indicating that CMV may not be a worrying case in this study.

\subsection{Model Assessment}

According to Henseler et al. (2009), there are two-steps process a researcher adopt to assess a reflective model in PLS-SEM path model. These comprises (1) the assessment of a measurement (outer) model, and (2) the assessment of a structural (inner) model.

\subsection{Assessment of Measurement Model}

Measurement model estimates the contribution of each item in representing its related latent variable (Hair et al., 2014). Researchers assess outer model by determining measurement reliability (individual item and internal consistency) and measurement validity (convergent and discriminant) (Hair et al., 2014). According to Henseler et al. (2016, p.10), "If the specified measurement (or outer) model does not possess minimum required properties of acceptable reliability and validity, then the structural (inner) model estimates become meaningless". Therefore, to assess the outer model in this study, measurement validity and reliability were examined. To ascertain measurement validity of the reflective measurement models in this study, convergent and discriminant validity were conducted. Convergent validity evidence is achieved when "different indicators of theoretically similar or overlapping constructs are strongly interrelated" and discriminant validity evidence is achieved when "indicators of theoretically distinct constructs are not highly intercorrelated" (Brown, 2015, p. 2).

Table 2

Loadings, Composite Reliability and Average Variance Extracted

\begin{tabular}{|c|c|c|c|c|c|}
\hline Constructs & Items & Loadings & rho $\mathrm{A}$ & $\mathbf{C R}^{\mathrm{a}}$ & $\mathbf{A V E}$ \\
\hline \multirow[t]{5}{*}{ CS } & CSS1 & 0.750 & 0.871 & 0.898 & 0.637 \\
\hline & CSS2 & 0.792 & & & \\
\hline & $\mathrm{CSS} 3$ & 0.836 & & & \\
\hline & CSS4 & 0.855 & & & \\
\hline & CSS5 & 0.753 & & & \\
\hline \multirow[t]{4}{*}{ PCA } & PCA1 & 0.770 & 0.771 & 0.848 & 0.582 \\
\hline & PCA2 & 0.780 & & & \\
\hline & PCA3 & 0.803 & & & \\
\hline & PCA4 & 0.694 & & & \\
\hline \multirow[t]{4}{*}{ PFA } & PFA2 & 0.568 & 0.783 & 0.801 & 0.508 \\
\hline & PFA3 & 0.674 & & & \\
\hline & PFA4 & 0.710 & & & \\
\hline & PFA5 & 0.866 & & & \\
\hline \multirow[t]{4}{*}{ ECC } & KUT1 & 0.848 & 0.872 & 0.910 & 0.718 \\
\hline & KUT2 & 0.872 & & & \\
\hline & KUT3 & 0.872 & & & \\
\hline & KUT4 & 0.794 & & & \\
\hline \multirow[t]{6}{*}{ ECR } & CDR4 & 0.656 & 0.820 & 0.868 & 0.525 \\
\hline & CDR6 & 0.741 & & & \\
\hline & CDR7 & 0.786 & & & \\
\hline & CDR8 & 0.720 & & & \\
\hline & CDR9 & 0.700 & & & \\
\hline & CDR10 & 0.737 & & & \\
\hline
\end{tabular}


In other words, convergent validity basically expresses whether latent variable indicators belong to that latent variable in question, and discriminant validity basically shows whether latent variable indicators in question do not fit into other latent variables in the same model (Levine, 2016; Wang et al., 2015). The former is determined by examining the loadings, average variance extracted (AVE) as well as composite reliability (CR). As shown in Table 2 and Fig. 2, the loadings were all beyond the standard value of 0.5 and the values of CR, rho_A are $>0.7$ and AVE $>0.5$ (Hair et al., 2013; Hair et al., 2009) and hence, convergent validity is achieved.

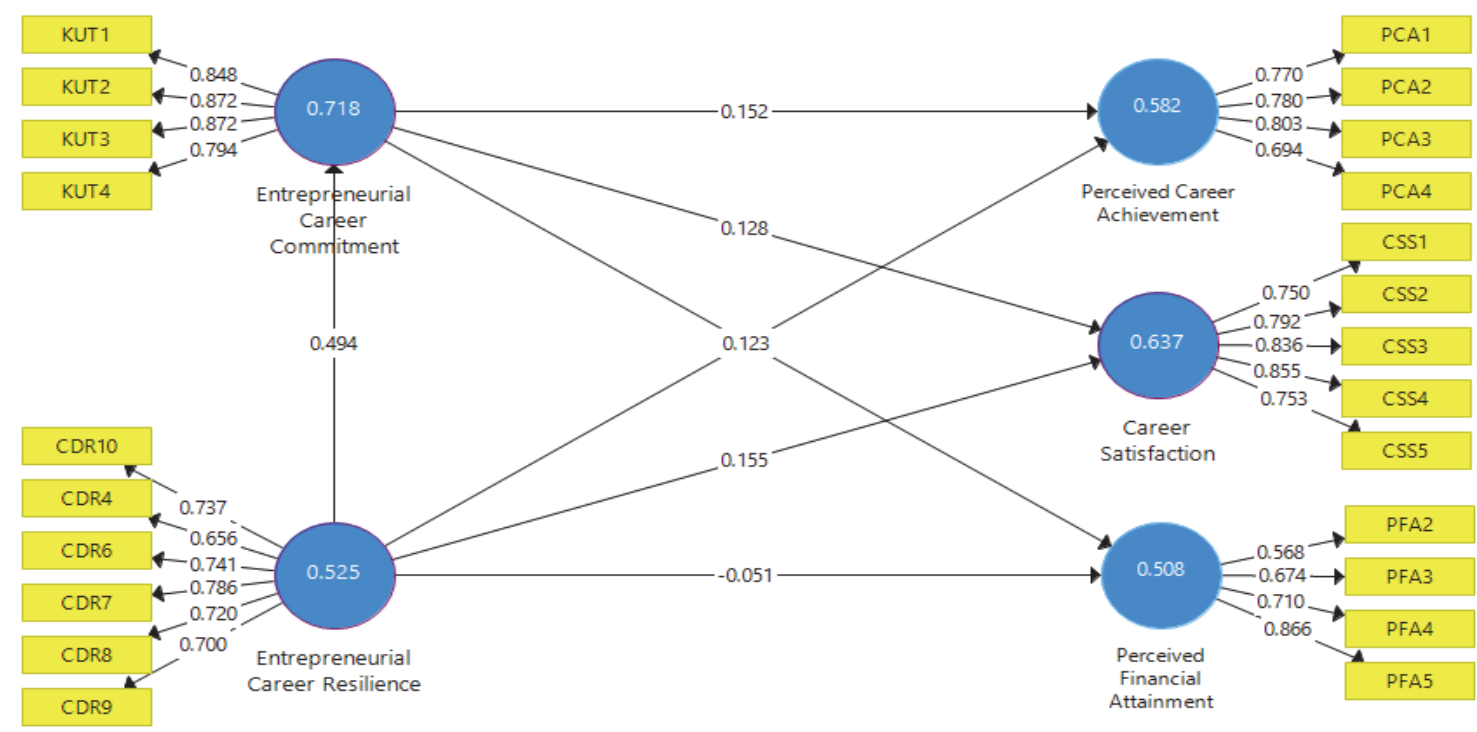

Fig. 2. Measurement model

The latter, on the other hand, is assessed using three criteria, AVE-SV (Fornell \& Larcker, 1981), cross loadings and heterotrait-monotrait (HTMT) matrix. Using the AVE-SV technique of corresponding the $(\sqrt{A V E})$ with the correlations among constructs which has been dominant in assessing discriminant validity for decades (Henseler et al., 2015), in this paper, the diagonal values, were greater than the horizontal and vertical values. According to this technique therefore, the measures in this study attained discriminant validity (see table 3 ).

\section{Table 3}

Fornell-Larcker Discriminant Validity Criteria (AVE-SV Comparison)

\begin{tabular}{lccccc}
\hline Constructs & CS & ECC & ECR & PCA & PFA \\
\hline CS & $\mathbf{0 . 7 9 8}$ & & & & \\
ECC & 0.204 & $\mathbf{0 . 8 4 7}$ & 0.494 & $\mathbf{0 . 7 2 4}$ & \\
ECR & 0.218 & 0.282 & 0.338 & $\mathbf{0 . 7 6 3}$ & \\
PCA & 0.493 & 0.097 & 0.009 & 0.263 & $\mathbf{0 . 7 1 3}$ \\
PFA & 0.406 &
\end{tabular}

Cross loadings (item-level discriminant validity) criterion is more substantial in assessing discriminant validity than the former (Henseler et al., 2015). Its assessment will support discriminant validity when the AVE-SV criteria fails to do so (Hair et al., 2012a,b; Henseler et al., 2009). For discriminant validity to be achieved, the loadings of each item must be greater than its cross-loadings. If not, then the measure is unable to discriminate as to whether it belongs to the construct it was intended to measure or to another and hence there is discriminant validity issue (Chin 2010). In this study, Table 4 shows that all item loadings are greater than their cross-loadings and therefore, discriminant validity is achieved. 
Table 4

Loadings and Cross loadings

\begin{tabular}{llrrrrr}
\hline Constructs & Items & CS & \multicolumn{1}{c}{ ECC } & ECR & PCA & PFA \\
\hline CS & CSS1 & $\mathbf{0 . 7 5 0}$ & 0.109 & 0.104 & 0.354 & 0.383 \\
& CSS2 & $\mathbf{0 . 7 9 2}$ & 0.171 & 0.174 & 0.383 & 0.310 \\
& CSS3 & $\mathbf{0 . 8 3 6}$ & 0.16 & 0.175 & 0.442 & 0.390 \\
& CSS4 & $\mathbf{0 . 8 5 5}$ & 0.188 & 0.206 & 0.431 & 0.319 \\
ECC & CSS5 & $\mathbf{0 . 7 5 3}$ & 0.166 & 0.183 & 0.350 & 0.251 \\
& KUT1 & 0.179 & $\mathbf{0 . 8 4 8}$ & 0.403 & 0.239 & 0.082 \\
& KUT2 & 0.208 & $\mathbf{0 . 8 7 2}$ & 0.410 & 0.249 & 0.165 \\
ECR & KUT3 & 0.198 & $\mathbf{0 . 8 7 2}$ & 0.426 & 0.263 & 0.058 \\
& KUT4 & 0.099 & $\mathbf{0 . 7 9 4}$ & 0.437 & 0.200 & 0.018 \\
& CDR4 & 0.214 & 0.327 & $\mathbf{0 . 6 5 6}$ & 0.282 & 0.007 \\
& CDR6 & 0.140 & 0.409 & $\mathbf{0 . 7 4 1}$ & 0.219 & -0.015 \\
& CDR7 & 0.216 & 0.353 & $\mathbf{0 . 7 8 6}$ & 0.241 & -0.010 \\
PCA & CDR8 & 0.052 & 0.388 & $\mathbf{0 . 7 2 0}$ & 0.192 & 0.020 \\
& CDR9 & 0.102 & 0.301 & $\mathbf{0 . 7 0 0}$ & 0.237 & 0.062 \\
& CDR10 & 0.199 & 0.362 & $\mathbf{0 . 7 3 7}$ & 0.287 & -0.011 \\
& PCA1 & 0.381 & 0.279 & 0.302 & $\mathbf{0 . 7 7 0}$ & 0.208 \\
PFA & PCA2 & 0.436 & 0.194 & 0.202 & $\mathbf{0 . 7 8 0}$ & 0.211 \\
& PCA3 & 0.407 & 0.234 & 0.216 & $\mathbf{0 . 8 0 3}$ & 0.180 \\
& PCA4 & 0.287 & 0.132 & 0.287 & $\mathbf{0 . 6 9 4}$ & 0.200 \\
\hline & PFA2 & 0.330 & 0.046 & 0.048 & 0.221 & $\mathbf{0 . 5 6 8}$ \\
& PFA3 & 0.255 & 0.082 & 0.053 & 0.102 & $\mathbf{0 . 6 7 4}$ \\
& PFA4 & 0.258 & 0.051 & -0.011 & 0.183 & $\mathbf{0 . 7 1 0}$ \\
& PFA5 & 0.353 & 0.087 & -0.022 & 0.257 & $\mathbf{0 . 8 6 6}$ \\
\hline
\end{tabular}

Recently, the latter two were challenged for their inability to detect no discriminant validity situation and having low sensitivity regarding assessing discriminant validity (Henseler et al., 2015). So, a new criterion, "HTMT matrix" was introduced, which exhibits better result than the traditional Fornell-Larcker and cross loadings (Henseler et al., 2015). HTMT could be assessed in two ways (criterion or statistical test). The former is calculated using PLS algorithms and involves matching the values to a certain benchmark. If its value is less than this benchmark, then discriminant validity is achieved. Kline (2015) suggested a cut-off of 0.85. The latter, HTMT inference, (Franke \& Sarstedt, 2018) is assessed through bootstrapping, which allows for creating confidence intervals for the HTMT. A confidence interval having the value of 1 shows the lack of discriminant validity. But, if the value is $<1$, then these two constructs are empirically different. In this paper, none of the values in the matrix (table 5) was greater or equals to the benchmark. Also, the highest upper limit confidence interval value was $<1(0.682)$. Therefore, the discriminant validity was achieved.

Table 5

Heterotrait-Monotrait (HTMT) Ratio \& Inferences

\begin{tabular}{|c|c|c|c|c|c|}
\hline Constructs & CS & ECC & ECR & PCA & PFA \\
\hline $\mathrm{CS}$ & & & & & \\
\hline ECC & $\begin{array}{c}0.228 \\
\mathrm{CI}_{85}(0.144,0.314)\end{array}$ & & & & \\
\hline ECR & $\begin{array}{c}0.245 \\
\mathrm{CI}_{85}(0.160,0.332)\end{array}$ & $\begin{array}{c}0.586 \\
\mathrm{CI}_{85}(0.510,0.657)\end{array}$ & & & \\
\hline PCA & $\begin{array}{c}0.607 \\
\mathrm{CI}_{85}(0.522,0.682)\end{array}$ & $\begin{array}{c}0.336 \\
\mathrm{CI}_{85}(0.228,0.433)\end{array}$ & $\begin{array}{c}0.415 \\
\mathrm{CI}_{85}(0.322,0.503)\end{array}$ & & \\
\hline PFA & $\begin{array}{c}0.547 \\
\mathrm{CI}_{85}(0.445,0.638)\end{array}$ & $\begin{array}{c}0.122 \\
\mathrm{CI}_{85}(0.066,0.161)\end{array}$ & $\begin{array}{c}0.097 \\
\mathrm{CI}_{85}(0.073,0.090)\end{array}$ & $\begin{array}{c}0.364 \\
\mathrm{CI}_{85}(0.252,0.470)\end{array}$ & \\
\hline
\end{tabular}


Table 6

Structural Model Assessment (Direct Effect)

\begin{tabular}{|c|c|c|c|c|c|c|c|c|}
\hline \multirow[t]{2}{*}{ Relationships } & \multirow{2}{*}{$\begin{array}{l}\text { Std. } \\
\text { Beta }\end{array}$} & \multirow{2}{*}{$\begin{array}{c}\text { Std. } \\
\text { Error }\end{array}$} & \multirow{2}{*}{ t-values } & \multirow{2}{*}{$\begin{array}{c}\text { p-val- } \\
\text { ues }\end{array}$} & \multicolumn{2}{|c|}{$\begin{array}{c}\text { Confidence In- } \\
\text { terval }\end{array}$} & \multirow[t]{2}{*}{$\mathbf{F}^{2}$} & \multirow[t]{2}{*}{ Decision } \\
\hline & & & & & $\mathbf{L L}$ & $\mathbf{U L}$ & & \\
\hline $\mathrm{ECR} \rightarrow \mathrm{CS}$ & 0.155 & 0.058 & $2.685 * *$ & 0.004 & 0.424 & 0.553 & 0.029 & Supported \\
\hline $\mathrm{ECR} \rightarrow \mathrm{PCA}$ & 0.263 & 0.056 & $4.671 * *$ & 0.000 & 0.164 & 0.348 & 0.023 & Supported \\
\hline $\mathrm{ECR} \rightarrow \mathrm{PFA}$ & -0.051 & 0.106 & 0.483 & 0.314 & -0.189 & 0.165 & 0.000 & Not Supported \\
\hline $\mathrm{ECR} \rightarrow \mathrm{ECC}$ & 0.494 & 0.040 & $12.494 * *$ & 0.000 & 0.048 & 0.238 & 0.288 & Supported \\
\hline $\mathrm{ECC} \rightarrow \mathrm{CS}$ & 0.128 & 0.054 & $2.343^{* *}$ & 0.010 & 0.030 & 0.210 & 0.032 & Supported \\
\hline $\mathrm{ECC} \rightarrow \mathrm{PCA}$ & 0.152 & 0.062 & $2.442 * *$ & 0.007 & 0.043 & 0.249 & 0.061 & Supported \\
\hline $\mathrm{ECC} \rightarrow$ PFA & 0.123 & 0.072 & $1.699 *$ & 0.045 & -0.137 & 0.188 & 0.021 & Supported \\
\hline
\end{tabular}

Note: **Significant at 0.01 (1-tailed), *significant at 0.05 (1-tailed)

\subsection{Testing the Direct Effects}

In testing the direct effect, we first, determine the effect of ECR on ECS as depicted in Table 6 and Fig. 3. We found that ECR was positively related to CS and PCA, $(\beta=0.155, t=2.685, p=0.001, \beta=0.263$, $\mathrm{t}=4.671, \mathrm{p}=0.000$, respectively) but it was not related to PFA $(\beta=-0.051, \mathrm{t}=0.483, \mathrm{p}=0.314)$. Thus, $\mathrm{H}^{1}$ and $\mathrm{H}^{2}$ were supported and $\mathrm{H}^{3}$ was not supported. Second, we determine the effect of ECR on ECC $(\beta=$ $0.494, \mathrm{t}=12.494, \mathrm{p}=0.000)$. Thus, $\mathrm{H}^{4}$ was supported. Third, we also assess the relationship between $\mathrm{ECC}$ and ECS. ECC was positively related to both CS and PCA, and PFA $\left(\beta=0.128^{\circ}, \mathrm{t}=2.343, \mathrm{p}=0.010, \beta=\right.$ $0.152, \mathrm{t}=2.442, \mathrm{p}=0.007$ and $\beta=0.123, \mathrm{t}=1.699, \mathrm{p}=0.045$ respectively). and therefore, the $\mathrm{H}^{5}, \mathrm{H}^{6}$ and $\mathrm{H}^{7}$ were supported. Overall therefore, this study tested seven direct relationships and found all but one to be significant.

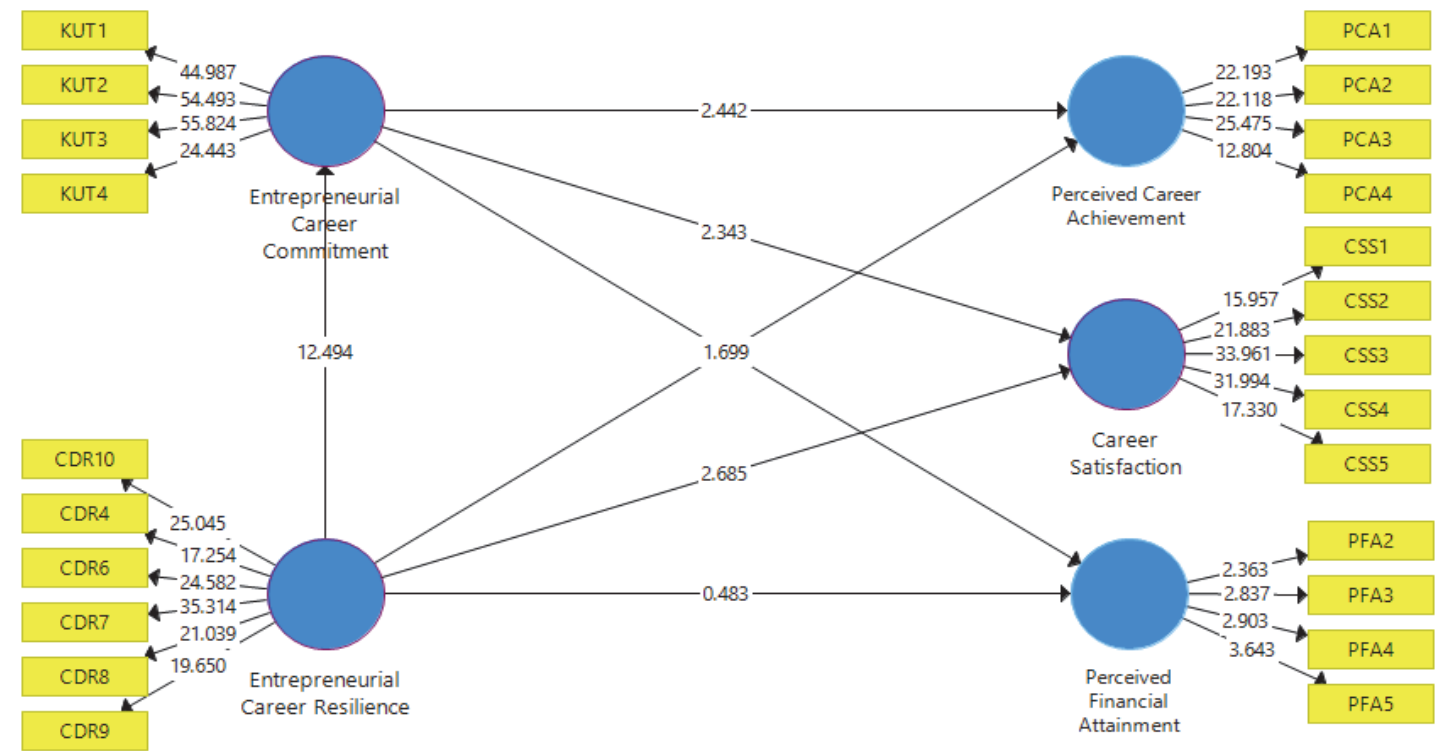

Fig. 3. Structural Model Assessment (Direct Effect)

\subsection{Testing the Indirect Effect}

In assessing the indirect effect, there are so many existing statistical techniques in use such as asymptotic/traditional (Baron \& Kenny, 1986; Sobel, 1982; Ringle et al., 2012), resampling/bootstrapping 
(Shrout \& Bolger, 2002), an analytical approximation to the distribution of the product (DPR) (MacKinnon et al., 2007), a Monte Carlo approximation to the DPR (Preacher \& Selig, 2012), etc. These methods have their own merit/demerit in terms of interpretation, software availability, empirical performance and computational ease (Falk \& Biesanz, 2016). But, this study used bootstrapping approach in Smart-PLS (Hair et al., 2014). An indirect effect is considered statistically significant when p-value is $<0.05$ or the CIs do not contain zero value in between. The bootstrapping result in Table 7, shows the mediating ability of ECC in the relationship between ECR and CS, ECR and PCA and hence $\mathrm{H}^{8}$, an $\mathrm{H}^{9}$ were supported. But, ECC did not mediate between ECR and PFA, hence, $\mathrm{H}^{10}$ was not supported.

\section{Table 7}

Result of Mediation Effect (Hypotheses testing) Using Bootstrapping

\begin{tabular}{|c|c|c|c|c|c|c|c|}
\hline \multirow[b]{2}{*}{ Relationships } & \multirow[b]{2}{*}{ Std. Beta } & \multirow[b]{2}{*}{ Std. Error } & \multirow[b]{2}{*}{ t-value } & \multirow[b]{2}{*}{$\mathrm{p}$-values } & \multicolumn{2}{|c|}{$\begin{array}{c}\text { Confidence } \\
\text { Interval }\end{array}$} & \multirow[b]{2}{*}{ Decision } \\
\hline & & & & & $\begin{array}{l}\text { Lower } \\
\text { Limit }\end{array}$ & $\begin{array}{l}\text { Upper } \\
\text { Limit }\end{array}$ & \\
\hline $\mathrm{ECR} \rightarrow \mathrm{ECC} \rightarrow \mathrm{CS}$ & 0.063 & 0.066 & 2.287 & $0.022 * *$ & 0.006 & 0.115 & Supported \\
\hline $\mathrm{ECR} \rightarrow \mathrm{ECC} \rightarrow \mathrm{PCA}$ & 0.075 & 0.077 & 2.318 & $0.020 * *$ & 0.011 & 0.139 & Supported \\
\hline $\mathrm{ECR} \rightarrow \mathrm{ECC} \rightarrow \mathrm{PFA}$ & 0.061 & 0.066 & 1.649 & 0.099 & -0.083 & 0.104 & Not supported \\
\hline
\end{tabular}

\subsection{Assessment of Structural Model}

Deciding on a model based on one criteria (e.g. $\mathrm{R}^{2}$ value only) is not a noble approach (Hair et al., 2016), as such, there is a need to examine different criteria before selecting a model. Therefore, to examine the structural model, often, explanatory and predictive power are being used. The former is determined using two criteria, (1) coefficient of determination $\left(\mathrm{R}^{2}\right)$ and (2) effect size. The latter on the other hand, is also determined using two criteria, (1) path coefficient $(\beta)$ and (2) predictive relevance $\left(Q^{2}\right)$.

\subsection{Coefficient of Determination $\left(R^{2}\right)$}

In PLS, the values of $\mathrm{R}^{2}$ symbolises the degree of variance in the construct(s), which is explained by the model. For $\mathrm{R}^{2}$ to have a significant level of explanatory power, it needs to be substantially adequate. An average $\mathrm{R}^{2}$ values are adequate when a few exogenous latent variables (LVs) explain the endogenous LV (Henseler et al., 2009). In the current study, to obtain the values of $\mathrm{R}^{2}$, the PLS algorithm was run. The ECR and ECC explained $18 \%$ of total variance in CS, $24.1 \%$ in PCA and $12.4 \%$ in PFA. While ECR explained $13.2 \%$ of total variance in ECC. The $\mathrm{R}^{2}$ values in this study are average and therefore considered adequate in explaining the variance in endogenous variables.

\subsection{Effect Size $\left(f^{2}\right)$}

In addition to estimating the $\mathrm{R}^{2}$ values of all endogenous variables in the model, the variation in the value of $\mathrm{R}^{2}$ when identified exogenous variable is removed from the model can be calculated to assess the substantial value of the removed variable on the endogenous variable. In other word, what contribution does exogenous variable makes to the $\mathrm{R}^{2}$ values? Does its removal cause significant increase in the $\mathrm{R}^{2}$ values or not? Which exogenous variable contributes more to the $\mathrm{R}^{2}$ values? According to Cohen (1988), if $\mathrm{f}^{2}=0.02$ it has small effect, $\mathrm{f}^{2}=0.15$ it has medium effect and $\mathrm{f}^{2}=0.35$ it has large effect. The $\mathrm{f}^{2}$ values of the current study is presented in Table 4.

\subsection{Predictive Relevance $\left(Q^{2}\right)$}

According to Hair et al. (2016), in addition to assessing $\mathrm{R}^{2}$, the $\mathrm{Q}^{2}$ value should be incorporated together to explain the predictive relevance. Using blindfolding procedure in PLS-SEM, $\mathrm{Q}^{2}$ values $>0$ means that the predictor variable possesses the predictive relevance for the criterion variable (Hair et al., 2011; Chin; 2010). The $\mathrm{Q}^{2}$ values of in Table 6 signify that the research model has good predictive relevance. 
Table 8

Predictive Capability of the Model (Construct Cross-Validated Redundancy)

\begin{tabular}{lccc}
\hline Constructs & SSO & SSE & $\mathbf{Q}^{\mathbf{2}}$ (=1-SSE/SSO) \\
\hline CS & $1,950.00$ & $1,887.23$ & 0.032 \\
PCA & $1,560.00$ & $1,455.57$ & 0.067 \\
PFA & $1,560.00$ & $1,558.57$ & 0.007 \\
ECC & $1,560.00$ & $1,304.67$ & 0.164 \\
\hline
\end{tabular}

\section{Discussions}

Although, recently, literature relating career resilience, career commitment and career success has been increasing, there are still some knowledge gaps remained unfilled. This paper examined the relationship of these variables in a sample of entrepreneurs in Nigeria. As shown above, results provided support for the prepositions that ECR was positively related to both CS, PCA as well as ECC but was not related to PFA. In addition, ECC is significantly related to both CS, PCA and PFA. Also the paper found significant mediating influence of ECC on ECR and CS, ECR and PCA, but not on ECR and PFA.

The findings of this study corroborates and contributes to previous investigations in numerous ways. First, there is a strong evidence to support that ECR is positively related to both ECS and ECC. Its positive relationship with ECS on one hand was documented in various studies and therefore these novel findings authenticated the previous literature (e.g. Lee \& Cha, 2015). Its positive relationship with ECC on the other hand also corroborates with so many studies (Hasan, 2016; Linnenluecke, 2015; Lee, \& Cha, 2015). One reason for this finding is the important the construct of resilience is in predicting outcomes in many problems affected countries like Nigeria. This finding means that entrepreneurs in a turbulent environment can survive, succeed and be committed when they can absorb shocks, bounce back and forge ahead. Second, the result provided clear evidence that ECS is a function of how committed that entrepreneur is. The more committed, the more the success. This finding is also supporting the many other empirical findings that found positive relationship between ECC and career success of entrepreneurs (e.g. Lee et al., 2014; Shieh, 2014). Finally, we have found the relationships to be mediated by ECC. This signifies that although entrepreneurs have shown steadfastness no matter the turbulence leading to successful career, they need to also be committed. In other words, because they are resilient, entrepreneurs are committed which in turn bring them to success.

To the best of our knowledge, there were no preceding studies that surveyed and empirically validated the interconnections among ECR, ECC and ECS. Therefore, this is the first attempt to construct these variables into one model and examine their connectedness.

\section{Limitations and Directions for Future Study}

This study has several limitations. First, the nature of this study is cross-sectional and no causal conclusions can be drawn from the current results. Future research should overcome this limitation by using a longitudinal research design. Second, as participants rated themselves in the same measurement context, future research should seek to corroborate the current findings by using multiple sources or multiple time points for data collection. In addition, no any demographic variable (i.e., gender, age) was included in our analyses. This is due to the absence of data for these variables and we were unable to identify their effects in the sample used. Future research may consider examining these demographic and control variables including income and experience in predicting ECS. This study considered one aspect of ECS, i.e. subjective aspect, this is due to its importance to an entrepreneur according to GCT. Future research can use objective career success outcome such as income and social status to test whether or not there could be any variance. Psychological capital has four related aspects (Luthans et al., 2007) resilience, hope, optimism, and efficacy. In this study, we only concentrated on one aspect (resilience) to predict career 
success and commitment because of the nature of the environment of the current study. We found this construct to be very important in predicting the outcomes of this study. It would be worthwhile if future studies adopt other facets of psychological capital to predict career success of entrepreneur in different context. Lastly, we found career resilience as a good predictor of career commitment and we expected that career commitment could as well predict resilience. In other words, these constructs might have reciprocal relationship. But the method used to analyse this important relationship cannot detect this type of relationship. Future study can either use different statistical package that could accept reciprocal relationship or test them inversely (career commitment predict career resilience) to see whether they are predictors of each other.

\section{Conclusion}

This exploratory investigation has conveyed new understanding into career success and the significance of resilience and commitment within entrepreneurial context. Overall, from the results of the analysis, we were able to present ten relationships, seven direct and three indirect. All but two of these relationships were significant. However, this piece of work can only convey partial insight beyond the context in which the data were gathered. It is one of rare piece on determinants of career success in the entrepreneurial context, but the results of our sample means that more of this study around the world in this field are definitely desirable because of dissimilarities of the national cultures. These issues may shape entrepreneurial career development across nationalities. Since the core of entrepreneurship is usually culturally sensitive, future investigations should examine deeper, the definitions and elements of career success in different cultures. For its relevance, career success of entrepreneurs requires further investigation that would broaden the findings presented in this paper.

\section{References}

Abiola, T., \& Udofia, O. (2011). Psychometric assessment of the Wagnild and Young's resilience scale in Kano, Nigeria. BMC Research Notes, 4(1), 1

Abramson, D. M., Grattan, L. M., Mayer, B., Colten, C. E., Arosemena, F. A., Bedimo-Rung, A., \& Lichtveld, M. (2014). The Resilience Activation Framework: a conceptual model of how access to social resources promotes adaptation and rapid recovery in post-disaster settings. The Journal of Behavioral Health Services and Research, 42(1), $42-57$.

Arthur, M. B., Khapova, S. N., \& Wilderom, C. P. (2005). Career success in a boundaryless career world. Journal of organizational behavior, 26(2), 177-202.

Ayala, J. C., \& Manzano, G. (2014). The resilience of the entrepreneur. Influence on the success of the business. A longitudinal analysis. Journal of Economic Psychology, 42, 126-135.

Ballout, H. I. (2009). Career Commitment and career success: moderating role of self-efficacy. Career Development International, 14(7), 655-670.

Baron, R. M., \& Kenny, D. A. (1986). The moderator-mediator variable distinction in social psychological research: Conceptual, strategic, and statistical considerations. Journal of personality and social psychology, 51(6), 1173.

Bhamra, R. (2015). Organisational Resilience: Concepts, Integration, and Practice. CRC Press.

Biesanz, J. C., Falk, C. F., \& Savalei, V. (2010). Assessing mediational models: Testing and interval estimation for indirect effects. Multivariate Behavioral Research, 45(4), 661-701.

Bonanno, G. A., Romero, S. A., \& Klein, S. I. (2015). The Temporal Elements of Psychological Resilience: An Integrative Framework for the Study of Individuals, Families, and Communities. Psychological Inquiry, 26(2), 139-169.

Bonesrønning, H. (2004). Do the teachers' grading practices affect student achievement?. Education Economics, 12(2), 151-167.

Brown, T. A. (2015). Confirmatory factor analysis for applied research. Guilford Publications

Brush, C. G., Manolova, T. S., \& Edelman, L. F. (2008). Separated by a common language? Entrepreneurship research across the Atlantic. Entrepreneurship Theory and Practice, 32(2), 249-266. 
Bullough, A., \& Renko, M. (2013). Entrepreneurial resilience during challenging times. Business Horizons, 56(3), 343-350.

Campbell-Sills, L., \& Stein, M. B. (2007). Psychometric analysis and refinement of the Connor-Davidson Resilience Scale (CD-RISC): validation of a 10-item measure of resilience. Journal of Traumatic Stress, 20(6), 1019.

Chiang, Y. H., Shih, H. A., \& Hsu, C. C. (2014). High commitment work system, transactive memory system, and new product performance. Journal of Business Research, 67(4), 631-640.

Cho, M. S., Lee, S. S., \& Kim, J. H. (2014). Relationship of resilience and organizational commitment in dental hygienists. Journal of Korean society of Dental Hygiene, 14(5), 695-701.

Cohen, J. (1988). Statistical power analysis for the behavioral sciences. 2nd edition. Lawrence Erlbaum, Hillsdale, New Jersey

Connor, K. M., \& Davidson, J. R. (2003). Development of a new resilience scale: The Connor-Davidson resilience scale (CD-RISC). Depression and Anxiety, 18(2), 76-82.

Cooper, N., Estes, C. A., \& Allen, L. (2004). Bouncing back. Parks \& Recreation (Ashburn), 39(4), 28 35.

De Clercq, D., Lim, D. S., \& Oh, C. H. (2013). Individual-Level Resources and New Business Activity: The Contingent Role of Institutional Context. Entrepreneurship Theory and Practice, 37(2), 303-330.

Deci, E. L., \& Ryan, R. M. (1985). Intrinsic motivation and self-determination in human behavior. Springer Science and Business Media.

Dej, D., Shemla, M., \& Wegge, J. (2013). Entrepreneurs' creativity and innovation: a key to performance. In A-G. Tan (Ed.), Creativity and talent development. Berlin: Springer

Duchek, S. (2018). Entrepreneurial resilience: a biographical analysis of successful entrepreneurs. International Entrepreneurship and Management Journal, 14(2), 429-455.

Envick, B. R. (2004). Beyond human and social capital: The importance of positive psychological capital for entrepreneurial success. Academy of Entrepreneurship, 10(2), 13.

Falk, C. F., \& Biesanz, J. C. (2016). Two cross-platform programs for inferences and interval estimation about indirect effects in mediational models. SAGE Open, 6(1),1-13

Farrell, J. E., Hook, J. N., Ramos, M., Davis, D. E., Van Tongeren, D. R., \& Ruiz, J. M. (2015). Humility and relationship outcomes in couples: The mediating role of commitment. Couple and Family Psychology: Research and Practice, 4(1), 14.

Fayolle, A., \& Liñán, F. (2014). The future of research on entrepreneurial intentions. Journal of Business Research, 67(5), 663-666.

Fornell, C., \& Larcker, D. F. (1981). Evaluating structural equation models with unobservable variables and measurement error. Journal of Marketing Research, 39-50.

Franke, G., \& Sarstedt, M. (2018). Heuristics Versus Statistics in Discriminant Validity Testing: A Comparison of Four Procedures. Internet Research, forthcoming.

García, P. O., \& Capitán, Á. O. (2016). Elements that contribute to boost female entrepreneurship: A prospective analysis. Suma de Negocios, 7(15), 54-60.

Greenhaus, J. H., Parasuraman, S., \& Wormley, W. M. (1990). Effects of race on organizational experiences, job performance evaluations, and career outcomes. Academy of management Journal, 33(1), 64-86.

$\mathrm{Gu}, \mathrm{Q}$. (2014). The role of relational resilience in teachers' career-long commitment and effectiveness. Teachers and Teaching, 20(5), 502-529.

Hair, J. F., Ringle, C. M., \& Sarstedt, M. (2011). PLS-SEM: Indeed a silver bullet. Journal of Marketing Theory and Practice, 19(2), 139-152.

Hair, J. F., Ringle, C. M., \& Sarstedt, M. (2012). Editorial-Partial Least Squares: The Better Approach to Structural Equation Modeling?. Long Range Planning, 45(5-6), 312-319.

Hair, J. F., Ringle, C. M., \& Sarstedt, M. (2013). Editorial-Partial least squares: The better approach to structural equation modeling? Long Range Planning, 45(2012), 312-319.

Hair, J. F., Sarstedt, M., Pieper, T. M., \& Ringle, C. M. (2012). The use of partial least squares structural equation modeling in strategic management research: a review of past practices and recommendations for future applications. Long range planning, 45(5), 320-340. 
Hair, J. F., Sarstedt, M., Ringle, C. M., \& Mena, J. A. (2012). An assessment of the use of partial least squares structural equation modeling in marketing research. Journal of the Academy of Marketing Science, 40(3), 414-433.

Hair Jr, J.F. Sarstedt, M., Hopkins, L., \& G. Kuppelwieser, V. (2014). Partial least squares structural equation modeling (PLS-SEM) An emerging tool in business research. European Business Review, 26(2), 106-121.

Hair Jr, J. F., Hult, G. T. M., Ringle, C., \& Sarstedt, M. (2016). A primer on partial least squares structural equation modeling (PLS-SEM). Sage Publications.

Hasan, Z. (2016). Culture as a Mediator between Resilience, Empathy and Commitment. International Journal of Innovative Research and Development,5(2).

Hayward, M. L., Forster, W. R., Sarasvathy, S. D., \& Fredrickson, B. L. (2010). Beyond hubris: How highly confident entrepreneurs rebound to venture again. Journal of Business Venturing, 25(6), 569578.

Henseler, J., Hubona, G., \& Ray, P. A. (2016). Using PLS path modeling in new technology research: updated guidelines. Industrial Management \& Data Systems, 116(1), 2-20

Henseler, J., Ringle, C. M., \& Sinkovics, R. R. (2009). The use of partial least squares path modeling in international marketing. Advances in International Marketing, 20(1), 277-319.

Henseler, J., Ringle, C. M., \& Sarstedt, M. (2015). A new criterion for assessing discriminant validity in variance-based structural equation modeling. Journal of the Academy of Marketing Science, 43(1), 115-135.

Hussels, S., Koryak, O., \& Reinmoeller, P. (2013). Weathering the storms: Identifying attributes of entrepreneurs' resilience using repertory GRID technique (summary). Frontiers of Entrepreneurship Research, 33(4), 7.

Jakobsen, M., \& Jensen, R. (2015). Common method bias in public management studies. International Public Management Journal, 18(1), 3-30.

Judge, T. A., Higgins, C. A., Thoresen, C. J., \& Barrick, M. R. (1999). The big five personality traits, general mental ability, and career success across the life span. Personnel psychology, 52(3), 621-652.

Karavardar, G. (2014). Career Commitment, Subjective Career Success and Career Satisfaction in the Context of Hazelnut Processing Industry in Giresun/Turkey. International Journal of Business and Management, 9(6), 98.

Klein, H. J., Molloy, J. C., \& Brinsfield, C. T. (2012). Reconceptualizing workplace commitment to redress a stretched construct: Revisiting assumptions and removing confounds. Academy of Management Review,37(1), 130-151.

Klein, H. J., Cooper, J. T., Molloy, J. C., \& Swanson, J. A. (2014). The assessment of commitment: Advantages of a unidimensional, target-free approach. Journal of Applied Psychology, 99(2), 222.

Kline, R. B. (2015). Principles and practice of structural equation modeling. Guilford publications.

König, S., Langhauser, M., Cesinger, B., \& Leicht, R. (2012). Entrepreneurial Success In An Entrepreneurial Career-The Case Of Work-Life-Balance: Results From A Large Scale Survey In Germany. Babson College Entrepreneurship Research Conference, Babson College, Wellesley, MA.

Lau, V. P., Shaffer, M. A., \& Au, K. (2007). Entrepreneurial career success from a Chinese perspective: conceptualization, operationalization, and validation. Journal of International Business Studies, 38(1), 126-146.

Lee, E. J., \& Cha, P. (2015). Effects of Work Environment and Resilience on Job Satisfaction and Organisational commitment of Social Workers in Juvenile Reformatory Schools. Indian Journal of Science and Technology, 8(S1), 360-366.

Lee, L., Petter, S., Fayard, D., \& Robinson, S. (2011). On the use of partial least squares path modeling in accounting research. International Journal of Accounting Information Systems, 12(4), 305-328.

Lee, Y. J., Lee, I. C., \& Lin, C. L. (2014). The effects of employee satisfaction and leadership styles on organizational performance: Organizational commitment as a dual mediator. Asian Journal of Empirical Research, 4(2), 104-124.

Levine, T. R. (2016). Confirmatory Factor Analysis. The International Encyclopedia of Interpersonal Communication. 
Linnenluecke, M. K. (2015). Resilience in business and management research: a review of influential publications and a research agenda.International Journal of Management Reviews.

Liu, J. Y., Yang, J. P., Yang, Y., \& Liu, Y. H. (2015). The relationships among perceived organizational support, intention to remain, career success and self-esteem in Chinese male nurses. International Journal of Nursing Sciences, 2(4), 389-393.

Luthans, F., Avolio, B. J., Avey, J. B., \& Norman, S. M. (2007). Positive psychological capital: Measurement and relationship with performance and satisfaction. Personnel psychology, 60(3), 541-572.

MacKinnon, D. P., Fritz, M. S., Williams, J., \& Lockwood, C. M. (2007). Distribution of the product confidence limits for the indirect effect: Program PRODCLIN. Behavior research methods, 39(3), 384-389.

Meyer, J. P., \& Allen, N. J. (1991). A three-component conceptualization of organizational commitment. Human Resource Management Review, 1(1), 61-89.

Paige, R. C., \& Littrell, M. A. (2002). Craft retailers' criteria for success and associated business strategies. Journal of small business management,40(4), 314-331.

Pan, J., \& Zhou, W. (2015). How do employees construe their career success: An improved measure of subjective career success. International Journal of Selection and Assessment, 23(1), 45-58.

Paul, H., \& Garg, P. (2014). Factor Structure of the Resilience Scale-14: Insights from an Indian Sample. South Asian Journal of Management, 21(2), 71.

Payne, G. T., Moore, C. B., Griffis, S. E., \& Autry, C. W. (2011). Multilevel challenges and opportunities in social capital research. Journal of Management,37(2), 491-520.

Podsakoff, P. M., MacKenzie, S. B., Lee, J. Y., \& Podsakoff, N. P. (2003). Common method biases in behavioral research: a critical review of the literature and recommended remedies. Journal of applied psychology, 88(5), 879.

Podsakoff, P. M., MacKenzie, S. B., \& Podsakoff, N. P. (2012). Sources of method bias in social science research and recommendations on how to control it. Annual Review of Psychology, 63, 539-569.

Poon, J. M. (2004). Career commitment and career success: moderating role of emotion perception. Career development international, 9(4), 374-390.

Preacher, K. J., \& Selig, J. P. (2012). Advantages of Monte Carlo confidence intervals for indirect effects. Communication Methods and Measures, 6(2), 77-98.

Ramana, C. V., Aryasri, A. R., \& Nagayya, D. (2008). Entrepreneurial success in SMEs based on financial and non-financial parameters. The Icfai University Journal of Entrepreneurship Development, $5(2), 32-48$

Richtnér, A., \& Löfsten, H. (2014). Managing in turbulence: how the capacity for resilience influences creativity. RandD Management, 44(2), 137-151

Ringle, C. M., Sarstedt, M., \& Straub, D. (2012). A critical look at the use of PLS-SEM in MIS Quarterly. MIS Quarterly (MISQ), 36(1).

Robinson, G. F., Schwartz, L. S., DiMeglio, L. A., Ahluwalia, J. S., \& Gabrilove, J. L. (2016). Understanding Career Success and Its Contributing Factors for Clinical and Translational Investigators. Academic Medicine,91(4), 570-582.

Salisu, I., \& Hashim, N. (2017). A Critical Review of Scales Used in Resilience Research. IOSR Journal of Business and Management, 19(4), 23-33.

Salisu, I., Hashim, N., \& Galadanchi, A. H. (2018). Social capital and entrepreneurial career resilience: The role of entrepreneurial career commitment. Management Science Letters, 8.

Salisu, I., Hashim, N., Ismail, K., \& Isa, F. M. (2017). Mediating Effect of Entrepreneurial Career Resilience between Entrepreneurial Career Commitment and Entrepreneurial Career Success. International Journal of Economic Research, 14(19), 231-251.

Sarstedt, M., Ringle, C. M., Henseler, J., \& Hair, J. F. (2014). On the emancipation of PLS-SEM: A commentary on Rigdon (2012). Long range planning, 47(3), 154-160.

Seo, K. S., Kim, M., \& Park, J. (2014). Effects of resilience and job satisfaction on organizational commitment in korean-american registered nurses. Journal of Korean Academy of Nursing Administration, 20(1), 48-58. 
Shahbazfar, R., \& Zarei, E. (2014) Investigating the Relationship between General Health and Resilience with Organizational Commitment among the Employees of Kerman Motors. International Journal of Management Studies, 3(2), 127-134

Shane, S., Locke, E. A., \& Collins, C. J. (2003). Entrepreneurial motivation. Human Resource Management Review, 13, 257-279.

Sharma, J., \& Dhar, R. L. (2016). Factors influencing job performance of nursing staff: mediating role of affective commitment. Personnel Review, 45(1), 161-182.

Shieh, C. J. (2014). Effects of Organizational Commitment on CS of Employees and Work Value in Catering Industry. Revista de Cercetare şi Intervenţie Socială, (46), 118-130.

Shrout, P. E., \& Bolger, N. (2002). Mediation in experimental and nonexperimental studies: new procedures and recommendations. Psychological methods, 7(4), 422.

Sobel, M. E. (1982). Asymptotic confidence intervals for indirect effects in structural equation models. Sociological methodology, 13(1982), 290-312.

Srikanth, P. B., \& Israel, D. (2012). Career Commitment \& Career Success: Mediating Role of CS. Indian Journal of Industrial Relations, 48(1).

Tait, M. (2008). Resilience as a contributor to novice teacher success, commitment, and retention. Teacher Education Quarterly, 35(4), 57-75.

Walker, E., \& Brown, A. (2004). What success factors are important to small business owners? International Small Business Journal, 22(6), 577-594

Wang, X., French, B. F., \& Clay, P. F. (2015). Convergent and Discriminant Validity with Formative Measurement: A Mediator Perspective. Journal of Modern Applied Statistical Methods, 14(1), 11.

Zhang, L. J., \& Wu, A. (2009). Chinese senior high school EFL students' metacognitive awareness and reading-strategy use. Reading in a Foreign Language, 21(1), 37.

\section{Appendix 1: Constructs Measurements}

\begin{tabular}{ll}
$\begin{array}{l}\text { Entrepreneurial } \\
\text { Items code }\end{array}$ & Survey Items \\
\hline CDR1 & I am able to adapt to change \\
CDR2 & I can deal with whatever comes \\
CDR3 & I try to see humorous side of problems \\
CDR4 & Coping with stress can strengthen me \\
CDR5 & I tend to bounce back after illness or hardship \\
CDR6 & I can achieve goals despite obstacles \\
CDR7 & I can stay focused under pressure \\
CDR8 & I am not easily discouraged by failure \\
CDR9 & I think of self as strong person \\
CDR10 & I can handle unpleasant feelings \\
Source: Campbell-Sills and Stein, 2007
\end{tabular}

Entrepreneurial Career Commitment Scale

Items code Survey Items

KUT1 How committed are you to your career?

KUT2 To what extent do you care about your career?

KUT3 How dedicated are you to your career?

KUT4 To what extent have you chosen to be committed to your career?

Source: Klein et al., 2014 


\section{Entrepreneurial Career Success Scale}

\section{Code Survey Items}

\section{Career Satisfaction}

CSS1

CSS2

CSS3

CSS4

CSS5

Source: Greenhaus et al., 1990

\section{Perceived Career Achievement}

PCA1

PCA2

I have accomplished something valuable from my career

PCA3

I have fulfilled something I want to do from my career

PCA4

I have made some of my dreams come true from my career

Source: Lau et al., 2007

\section{Perceived Financial Attainment}

PFA1

PFA2

PFA3

PFA4

PFA5

Source: Lau et al., 2007
I have earned more money than most of my friends

As a businessperson, my income is almost at the highest level in the same industry What I have earned from my businesses is more than what I actually need I can be deemed a rich person

I earn a lot of money

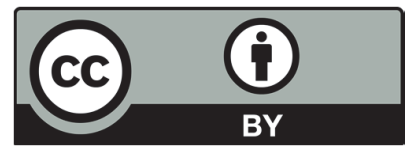

(C) 2019 by the authors; licensee Growing Science, Canada. This is an open access article distributed under the terms and conditions of the Creative Commons Attribution (CCBY) license (http://creativecommons.org/licenses/by/4.0/). 